\title{
Deformation due to the 17 August 1999 Izmit, Turkey, earthquake measured from SPOT images
}

\author{
Rémi Michel and Jean-Philippe Avouac \\ Laboratoire de Détection et de Géophysique, CEA, Bruyères-le-Châtel, France
}

Received 8 December 2000; revised 4 April 2001; accepted 31 August 2001; published 12 April 2002.

[1] The geometry of the ruptured areas and the coseismic slip distribution data are key to highlighting the behavior of seismic faults. This information is generally retrieved from field investigations and geodetic measurements or synthetic aperture radar (SAR) interferometry. Here we show that SPOT images can also be used to accurately map the fault zone and to determine the slip distribution by subpixel correlation of images acquired before and after an earthquake. The measured slip includes the contribution of possible distributed shear that might not be clearly expressed in surface ruptures and smoothes out possible along-strike variability due to near-surface fault complexities. We apply the technique to the $M_{s}=7.4,1999$, Izmit earthquake. Our results reveal a $<100$-m-wide and very linear fault zone that can be traced for $70 \mathrm{~km}$ from Gölcük to Akyazi, along which supershear rupture has been inferred. The obtained slip distribution compares well with the field measurements and is consistent with ground deformation measured at some distance from the fault zone using SAR images. Very little deformation was accommodated off the main fault plane. Maximum slip is observed near Sapanca lake at a small fault jog that has probably influenced rupture propagation. INDEX TERMS: 1242 Geodesy and Gravity: Seismic

deformations (7205); 1640 Global Change: Remote sensing; 5475 Planetology: Solid Surface

Planets: Tectonics (8149); KEYWORDS: earthquake, deformation, Izmit, offset

\section{Introduction}

[2] Fault ruptures geometry and coseismic displacements data are key to highlighting the behavior of seismic faults. This behavior is of interest in earthquake source studies because fault geometric complexities are known to influence rupture dynamics [Sibson, 1986; Harris et al., 1991; Barka and Kadinsky-Cade, 1988; Bouchon and Streiff, 1997; Aochi et al., 2000; Harris and Day, 1999; Kase and Kuge, 1998; Harris et al., 2000], hence seismic radiation, and because the coseismic slip distribution can be used to test dynamic rupture models [Bouchon and Streiff, 1997; Aochi et al., 2000]. A preliminary attempt to model spontaneous rupture during the Izmit earthquake taking into account the fault segmentation has been performed by Harris et al. [2000]. Conversely, such data are necessary to constrain the determination of the source kinematics from seismological records because there are various trade-offs between the geometric characteristics of the fault, the slip, and the rupture time distributions [Hernandez et al., 1999]. A good knowledge of fault geometry and coseismic slip is also needed to estimate coseismic stress changes and investigate aftershock triggering mechanisms and implications for the probability of rupture of other nearby faults [Stein, 1999; Hubert-Ferrari et al., 2000; Parsons et al., 2000].

[3] Geometry of fault ruptures and coseismic slip is generally obtained from field investigations and geodetic measurements. Field investigations consist of thorough mapping of surface breaks and measuring coseismic slip from dislocated features that can be matched across these breaks [Yeats et al., 1997; Weldon et al., 1996]. However, because of near-surface fault complexities the determination of the total slip across the fault zone is not straightforward. In addition, the zone of coseismic strain might be significantly broader than the zone where ruptures are clearly seen at the surface. In the case of the Landers earthquake it has been observed that anelastic shear may be distributed in a zone possibly as broad as

Copyright 2002 by the American Geophysical Union. 0148-0227/02/2000JB000102\$09.00
$1-2 \mathrm{~km}$ and may amount to as much as $20 \%$ of the total slip across the fault zone [Yeats et al., 1997; McGill and Rubin, 1999]. It is therefore not straightforward to assess whether the slip variability measured at the surface only relates to these near-surface complications or may reflect slip heterogeneity at depth.

[4] For these various reasons, any technique capable of providing reliable measurements of ground displacements near the fault zone would be most useful. Geodetic data are generally too sparse to constrain tightly the slip distribution. Differential synthetic aperture radar (SAR) interferometry [Massonnet et al., 1993; Zebker et al., 1994] generally fails in the near-fault zone where large displacements result in poorly correlated images and eventually signal decorrelation [Michel et al., 1999]. The use of subpixel correlation of SAR amplitude images can partially supplement interferometry as it provides an unambiguous measurement of both the track-parallel and track-perpendicular components of the ground displacement [Michel et al., 1999; Peltzer et al., 1999]. Unfortunately, temporal decorrelation of ERS amplitude images available for the Izmit earthquake is too large, and SAR images do not yield significant measurements near the faults. Following early attempts [Crippen, 1992], we have explored the possible use of optical imagery to measure ground displacements and developed specific algorithms [Van Puymbroeck et al., 2000]. This technique is applied here as a complement to radar interferometry for analyzing ground displacement during the Izmit earthquake.

\section{Setting of the Izmit Earthquake}

[5] The Izmit earthquake ruptured a segment of the North Anatolian fault (NAF) at the eastern tip of the Marmara Sea (Figure 1). This fault segment is part of a northern branch of the NAF which is thought to have accommodated $\sim 70 \mathrm{~km}$ of slip since $\sim 5$ Myr [Armijo et al., 1999]. GPS measurements [Straub and Kahle, 1997; McClusky et al., 2000] anterior to the Izmit earthquake revealed interseismic straining corresponding to $27 \pm$ $1 \mathrm{~mm} / \mathrm{yr}$ slip rate and a fault locking depth of $\sim 20 \mathrm{~km}$ [Reilinger 

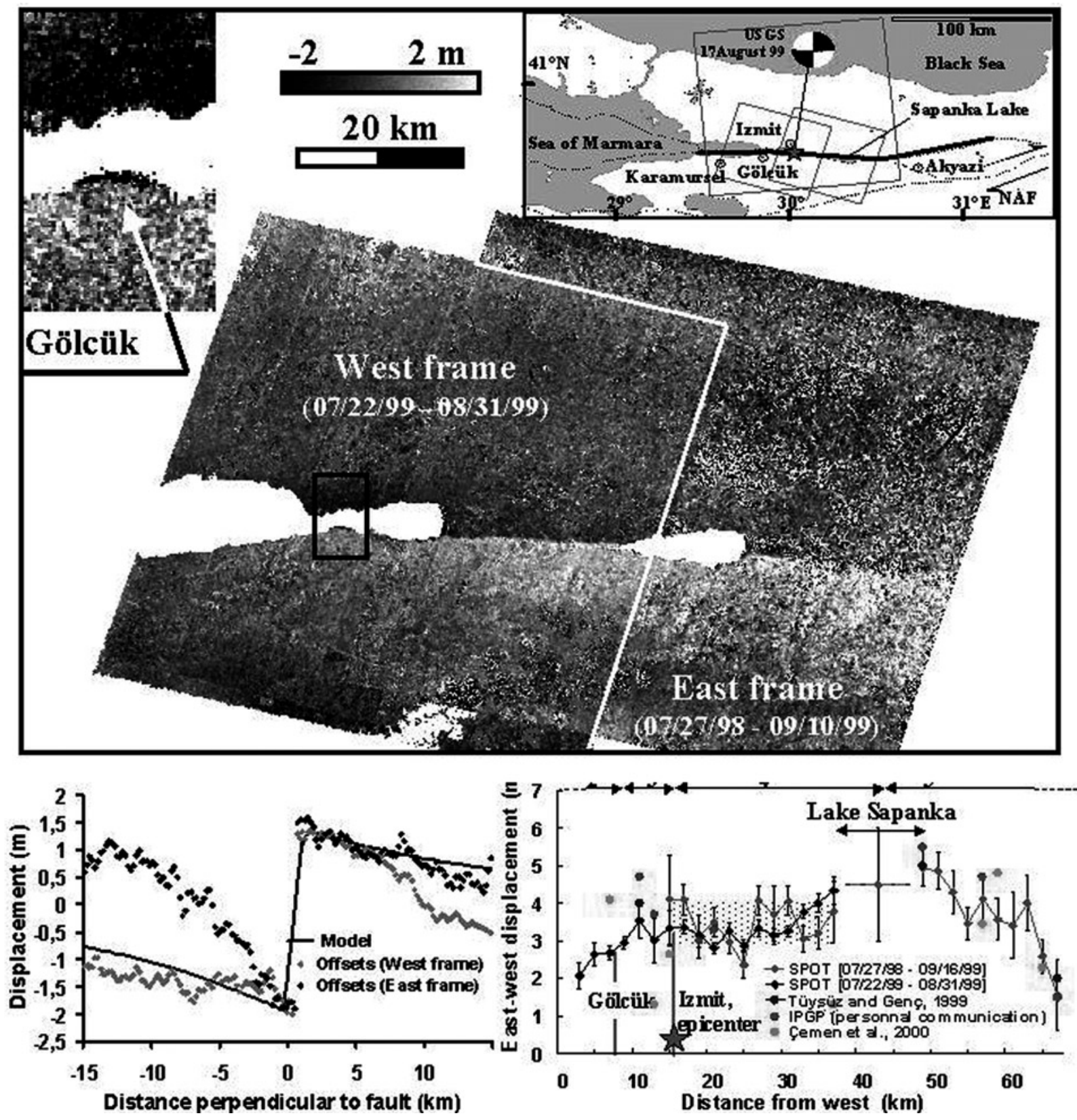

Figure 1. Ground displacement mapped from SPOT images. (a) E-W component of the displacement field computed from image pairs (KJ 102/268, SPOT-1 of 22 July 1999 and SPOT-2 of 31 August 1999) and (KJ 103/268, SPOT-2 of 27 July 1998 and SPOT-2 of 16 September 1999). The very linear discontinuity between Golcük and Akyazi coincides with the ruptures described from field survey. No deformation is visible out of this main fault zone. $\mathrm{N}-\mathrm{S}$ offsets are below the noise level. Tectonic setting, with main active faults, of the $M_{s}=7.4$, 17 August 1999 Izmit earthquake is given in inset. Focal mechanism is from USGS catalog, and epicenter (star) is from Kandilli Observatory. Shaded boxes denote location of SPOT and ERS images. Black lines show approximate location of ruptures described from field investigations. (b) Stack of all profiles across fault zone from Izmit to Sapanca lake. Offsets show a clear jump at the fault trace, indicating a fault zone $<200 \mathrm{~m}$ wide. Mean slip is $3.5 \pm 0.2 \mathrm{~m}$. The two profiles differ due to uncertainty on SPOT changing attitude. Shaded line shows theoretical displacements derived from elastic modeling (Table 1). (c) Slip distribution between Gölcük and Akyazi measured from 1-km-wide swaths across the fault. Uncertainties are estimated from the variability of offsets on each side of the fault. The estimated slip at Sapanca lake is ascribed a large uncertainty because it is based on linear extrapolation of offsets across the lake. Field measurements are shown for comparison. See color version of this figure at back of this issue.

et al., 2000]. The epicenter of the $M_{w}=7.4,17$ August earthquake is located close to Izmit [Toksök et al., 1999; Barka, 1999] (Figure 1). The source mechanism is purely strike-slip faulting on a vertical E-W fault [Barka, 1999; Tüysüz and Genc, 1999; Çemen et al., 2000]. According to local strong motions and teleseismic records the hypocentral depth was $\sim 15 \mathrm{~km}$ [Cemen et al., 2000; Ellsworth and Celebi, 1999]. The total seismic moment is estimated between 1.0 and $2.41020 \mathrm{~N} \mathrm{~m}$ [Toksök et al., 1999; Cemen et al., 2000]. Surface ruptures were observed for $\sim 120 \mathrm{~km}$ extending eastwest from Karamürsel to near Duzce [Barka, 1999; Tüysüz and 
Table 1. Fault Model Derived From SPOT Offsets and ERS-1 SAR Interferometry ${ }^{\mathrm{a}}$

\begin{tabular}{|c|c|c|c|c|c|c|c|}
\hline Fault Segment & $\begin{array}{l}\text { Center } \\
\text { Latitude, } \\
{ }^{\circ} \mathrm{N}\end{array}$ & $\begin{array}{c}\text { Center } \\
\text { Longitude, } \\
{ }^{\circ} \mathrm{E}\end{array}$ & $\begin{array}{l}\text { Length, } \\
\text { km }\end{array}$ & $\begin{array}{c}\text { Azimuth, } \\
{ }^{\circ} \mathrm{E}\end{array}$ & $\begin{array}{c}\text { Slip, } \\
\text { cm }\end{array}$ & $\begin{array}{l}\text { Averaged } \\
\text { Slip, } \\
\text { cm }\end{array}$ & $\begin{array}{c}\text { Depth, } \\
\text { km }\end{array}$ \\
\hline 1, Marmara & 40.719 & 29.462 & 16.64 & -92.203 & 200 & 100 & 15 \\
\hline 2, Karamürsel-Gölcük & 40.710 & 29.682 & 22.11 & -93.318 & 315 & 300 & 11.0 \\
\hline 3, Gölcük-Izmit & 40.718 & 29.869 & 10.00 & -83.56 & 315 & 300 & 13.6 \\
\hline 4, Izmit-Sapanca & 40.716 & 30.091 & 27.86 & -87.690 & 349 & 330 & 8.9 \\
\hline 5, Sapanca-Akyazi & 40.701 & 30.403 & 25.08 & -81.199 & 220 & 250 & 8.8 \\
\hline 6, Akyazi-Duzce & 40.720 & 30.739 & 32.61 & -101.310 & 100 & 130 & 10 \\
\hline
\end{tabular}

${ }^{a}$ All fault planes are vertical and reach the surface. Angles are given in degrees, and azimuth is given counterclockwise from due north.

${ }^{\mathrm{b}}$ Averaged value from Reilinger et al. [2000]; see text for discussion.

Genc, 1999; Çemen et al., 2000]. The ruptures probably extend west of Karamürsel, in the Gulf of Izmit and Marmara Sea as suggested from the aftershocks [Parsons et al., 2000]. From Karamürsel to Akyazi the fault strikes approximately E-W azimuths, is relatively linear with small jogs, and has accommodated right-lateral slip between 1 and $5 \mathrm{~m}$ [Barka, 1999; Çemen et al., 2000; Barka et al., 2000]. This fault portion is probably responsible for the main subevent in the bimodal source function [Çemen et al., 2000; Ellsworth and Celebi, 1999] and is characterized by a supershear rupture velocity [Bouchon et al., 2000]. It has been proposed that the bimodal source would also be reflected in the surface slip distribution with maximum slip east of Sapanca and near Golcük [Cemen et al., 2000]. The rupture of the easternmost segment, which strikes about $\mathrm{N} 65^{\circ} \mathrm{E}$ east of Akyazi, was apparently triggered late in the process [Barka, 1999]. Fields measurements indicate $<1.5 \mathrm{~m}$ of right-lateral slip along this segment [Barka, 1999; Tüysüz and Genc, 1999; Barka et al., 2000].

\section{Determination of the Fault Geometry and Slip From SPOT Images}

\subsection{Method}

[6] Ground deformation during an earthquake may be measured from comparison of optical images acquired before and after the seismic event [Van Puymbroeck et al., 2000]. We use pairs of SPOT images with near-vertical incidence in order to minimize stereoscopic disparities. The two images are first resampled in the same cartographic projection using a digital elevation model (DEM), a physical model of image acquisition, and an accurate interpolator. In our study we use a DEM derived from ERS SAR interferometry. During that initial processing, some artifacts due to the SPOT push-broom system are corrected together with misregistrations due to the changing attitude of SPOT during the acquisition of each image. Residual offsets are next computed from the phase shift of the Fourier transform of a sliding window. It yields the two horizontal components of the ground displacement and an estimate of errors. Spatial sampling and the accuracy of measurements mainly depend on the local level of correlation of the images. For the Izmit earthquake we get independent measurements every $160 \mathrm{~m}$ and an average uncertainty of 0.25 $m$ (1/40th of the pixel size). Offsets also include residual artifacts due to errors and undersampling of the roll, pitch, and yaw characterizing SPOT attitude. This latter source of error may introduce a significant apparent warping at spatial wavelengths larger than a few kilometers [Van Puymbroeck et al., 2000].

\subsection{Application to the Izmit Earthquake}

[7] We have focused our study on the main fault strand between Karamürsel and Akyazi. We used two pairs of SPOT images, one pair of ERS SAR images and a DEM derived from ERS images (Figure 1). Each pair spans the coseismic phase together with 15-25 days of postseismic deformation. The images were first corrected to account for various artifacts that cause misregistrations unrelated to ground deformations. The remaining offsets were then measured from the subpixel correlation technique described above. The E-W component (Figure 1a) shows a prominent approximately E-W discontinuity between Izmit and Akyazi that closely follows the surface ruptures mapped in the field [Tüysüz and Genc, 1999; Çemen et al., 2000]. Even the surface ruptures along the coast line from Gölcük to Izmit are visible (inset in Figure 1a). The N-S component of the displacement field is everywhere below the noise level, as expected from a nearly pure strike-slip motion. In order to investigate ground deformation in the fault zone we have drawn profiles perpendicular to the fault strike, by stacking all data along 1-km-wide swaths. All the profiles show a clear jump at the fault trace. Figure $1 \mathrm{~b}$ shows for example a stack of the 26 profiles along the Izmit-Sapanca fault segment, retrieved from the two pairs of SPOT images. The two sets of data show the same jump at the fault trace, but the patterns are actually quite different. The difference results from uncertainties on the attitude of SPOT during image acquisition. Fortunately, the satellite attitude does not vary rapidly enough to introduce as sharp gradients as those induced by coseismic deformation. The determination of the fault slip at the surface rupture is not biased. SPOT offsets suggest that the fault zone is nowhere wider than $\sim 200 \mathrm{~m}$, with a clear right-lateral offset of $3.5 \mathrm{~m}$ on average. This value is consistent with the 3-4 m slip reported from field investigations along this fault segment [Tüysüz and Genc, 1999]. The value is also in agreement with the displacement measurements by Çemen et al. [2000], who reported a gradual decrease in displacements from $\sim 4$ m near Golcuk to $1.3 \mathrm{~m} \sim 5 \mathrm{~km}$ west of Sapanca lake. They also reported that displacements increases again eastward and reaches to $\sim 5 \mathrm{~m}$ east of the town of Arifiye. Figure 1c shows the slip pattern derived from the 1-km spaced profiles drawn in the two offset fields. Average uncertainties of the measurements are 0.25 and $0.70 \mathrm{~m}$ for the west and east frames, respectively. Comparison between the measurements made from the two offsets fields suggests that measured uncertainties are probably slightly underestimated. The field measurements in Figure 1c appear to be close to our measurement of the total offset across the fault zone. Our estimate of the slip between Gölcük and Izmit seems small compared to the field measurements. This is probably due to uncertainty associated with the interpolation of offsets across Izmit Bay. The general consistency between field measurements and those made from SPOT images and the fact that the fault zone seems everywhere narrower than one pixel in the offset field $(160 \mathrm{~m})$ indicate that coseismic fault slip was entirely accommodated along the ruptures seen at the surface. We can conclude that there was little if any coseismic deformation taken up by distributed shear off the main fault's trace. Because field measurements generally show a complex fault geometry and a high variability of slip, with slip possibly varying by as much as a few meters over a few hundreds meters [Yeats et al., 1997; Weldon et al., 1996; McGill and Rubin, 1999], we should not expect a perfect match between $1-\mathrm{km}$ averaged values of the 
displacement across the whole fault zone obtained from our technique and local field measurements. In that respect, the surface ruptures associated with the Izmit earthquake seem remarkably simple. Note also that the generally high slip variability at the small scale implies that the estimate of the mean slip highly depends on the sampling in the field, so that a reliable estimate requires a very detailed survey [Yeats et al., 1997; Weldon et al., 1996]. Our technique is thus best adapted to yield a reliable estimate of the mean slip, together with some informa-
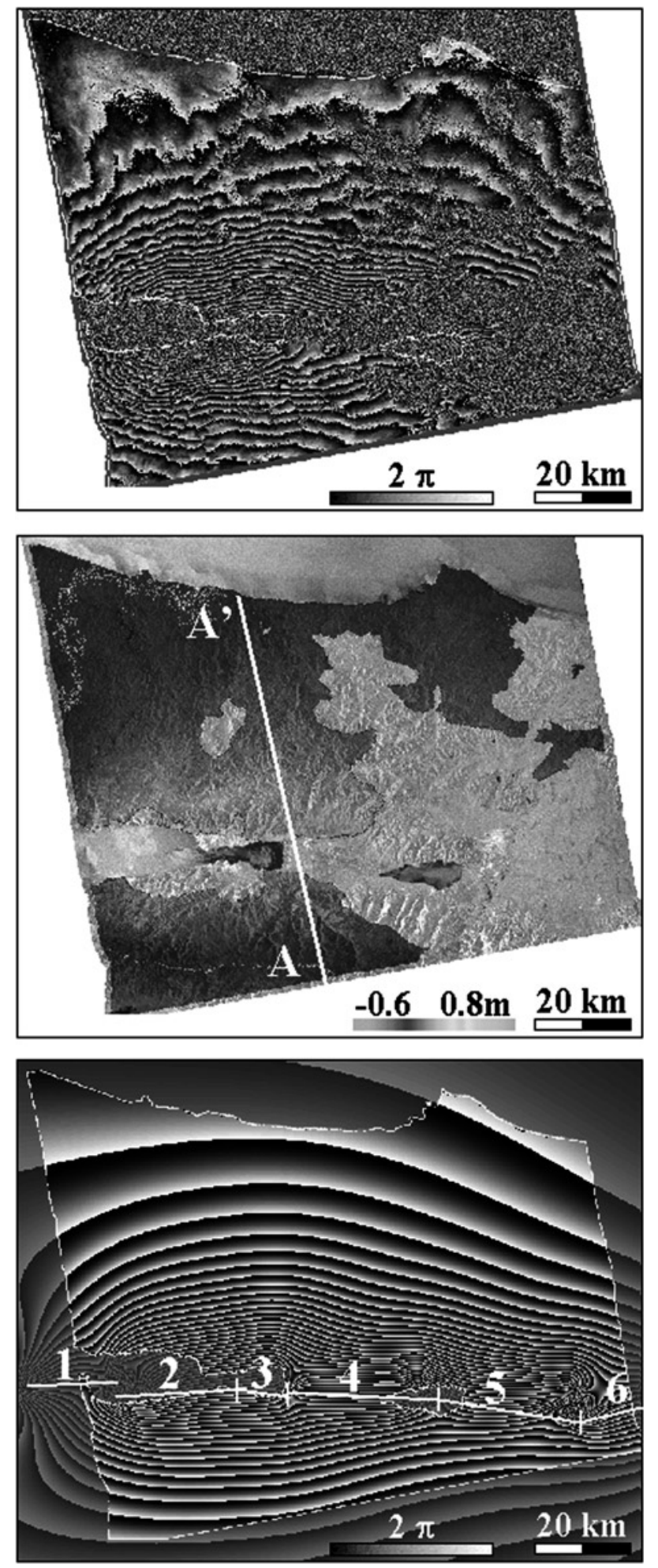

tion about possible distributed shear in the fault zone not clearly expressed in surface ruptures. It is also noteworthy that the slip variability measured from offsets (Figure 1) is much more regular than that derived from GPS data by Reilinger et al. [2000] though the values averaged at the segment scale are in good agreement (Table 1). This suggests that the model of Reilinger et al. [2000] is somewhat overdetermined as the number of free parameters in their model is greater than the number of GPS measurements available.

[8] In the present case we find mean slip of $3.2 \pm 0.5 \mathrm{~m}$ along the Karamürsel-Gölcük segment, $3.4 \pm 0.4 \mathrm{~m}$ along the GölcükIzmit segment, $3.5 \pm 0.2 \mathrm{~m}$ along the Izmit-Sapanca segment, and $2.2 \pm 0.6 \mathrm{~m}$ along the Sapanca-Akyazi segment (Table 1). The slip distribution obtained from our technique is rather smooth, with the zone of maximum slip, $\sim 5 \mathrm{~m}$, being observed around Sapanca lake. Unexpectedly, it seems that the near-surface fault slip tends to be maximum at the junction between the fault segments. The slip tapers gradually from Sapanca to Akyazi. Farther east, it continues to trail off from Akyazi to Duzce along N56 ${ }^{\circ} \mathrm{E}$ striking surface ruptures with slip between 1 and $1.5 \mathrm{~m}$ [Barka, 1999; Tüysüz and Genc, 1999]. We have not tried to document this zone of low slip from the SPOT images. It should be noted that field investigations around Sapanca lake have revealed much smaller offsets than those measured from SPOT images. This may suggest that near the fault jog at Sapanca lake, part of the coseismic deformation was accommodated in a distributed shear zone so that only a fraction of the total slip was accommodated in the main fault trace. More generally, the smoothness of the fault slip measured from the SPOT images suggests that the irregular fault slip distribution measured in the field reflects near-surface complexities in a shear zone only a few hundred meters wide.

\section{Consistency with SAR Measurements}

[9] We have complemented our study using ERS-1 SAR images by computing SAR interferograms [Massonnet et al., 1993; Zebker et al., 1994; Michel et al., 1999]. This technique provides the nearvertical component of the ground displacement (Figure 2). SAR interferograms are generally very noisy near the fault but provide

Figure 2. (opposite) Measured and modeled interferograms. (a) Differential SAR interferogram computed from ERS-2 SAR images (orbit frames 22556/815 and 23057/815) acquired on 13 August 1999 and 17 September 1999, respectively. A fringe represents $2.8 \mathrm{~cm}$ of ground shift away from satellite along the radar line of sight. Areas with a high level of noise result from temporal decorrelation. Near-fault areas are also poorly coherent due to either ground shaking or signal saturation. Interferogram is also affected by low-frequency noise (for wavelength larger than $\sim 10 \mathrm{~km}$ ) with an amplitude of a few fringes induced by atmospheric artifacts and residual errors in determination of orbits [e.g., Reilinger et al., 2000]. Orbital parameters tuned to remove a residual plane that cannot be explained by coseismic ground deformation. This linear correction amounts to three fringes in azimuth and four fringes in range. (b) Unwrapped interferogram. Phase unwrapping removes the $2 \pi$ ambiguity on measurements and yields relative displacements. Because the fault zone cuts across the interferogram, areas north and south of the fault zone are not related to the same reference frame, they were adjusted in order to fit elastic modeling. (c) Synthetic interferogram computed from the segmented fault model given in Table 1. We use an elastic halfspace dislocation model and consider vertical faults that reach the surface. Geometry and mean slip along the Karamürsel-Gölcük, Gölcük-Izmit, Izmit-Sapanca, and Sapanca-Akyazi segments were constrained from the offsets. The fault extents at depth and dip angle were adjusted for each segment. See color version of this figure at back of this issue. 

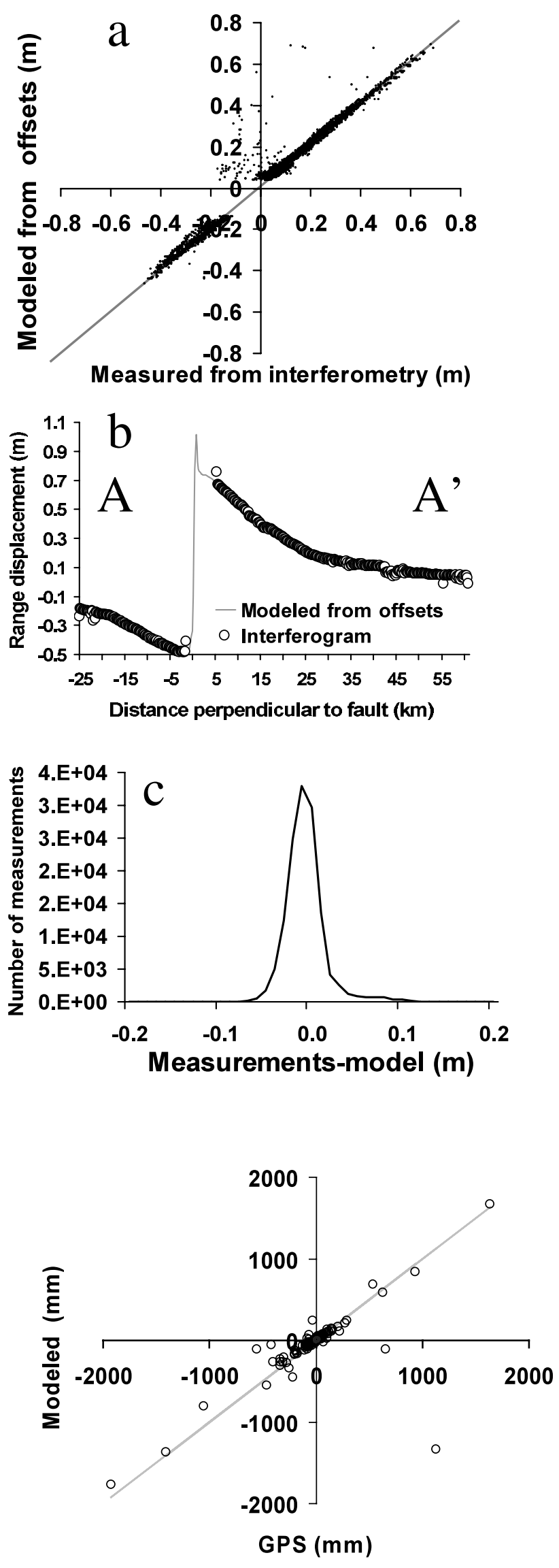

Figure 3. (opposite) Comparison of ground displacement measured from interferometry and computed from the fault model of Table 1. (a) The comparison is made along profile $\mathrm{AA}^{\prime}$; See Figure $2 b$ for location of profile. (b) Plot of observed versus theoretical displacements for the whole area covered by the unwrapped interferogram. Values closely follow the 1:1 linear trend and meet the origin. It attests to the quality of the adjustment and validates the assumption of no displacement in the far field. The points with negative displacements correspond to the area south of the fault. The reference frame for this area is adjusted so that these points also fall on the linear 1-1 trend trough the origin. (c) Histogram of the difference between the observed and modeled displacements. It shows that the model fits the measurements to better than $5 \mathrm{~cm}$. Nearly all the information contained in the interferogram is accounted for by the simple six-segment fault model of Table 1. (d) Comparison between the proposed model and 51 coseismic GPS measurement available [Reilinger et al., 2000]. RMS error $(6.5 \mathrm{~cm})$ is in agreement with noise on measurements. 
sponds to a static moment of about $1.1 \times 10^{20} \mathrm{~N} / \mathrm{m}^{2}$ in the lower range of seismic estimates.

\section{Implications and Conclusion}

[10] Our study demonstrates that the geometric disparities between SPOT images (offsets) acquired before and after an earthquake provide constraints on the geometry of the fault zone, with an accuracy of the order of $100 \mathrm{~m}$, and on the average fault slip, with an accuracy of $\sim 50 \mathrm{~cm}$ for $1-\mathrm{km}$ spaced measurements. It allows some averaging of high-frequency slip variations induced by the near-surface fault complexity and yields a measurement of the total slip accommodated across the whole fault zone, including possible off-the-main-fault deformation. Applied to the Izmit earthquake, our technique reveals a higher coseismic slip at the fault junction near Sapanca lake and possibly also near Izmit and Gölcük. Our data thus tend to support the bimodal slip distribution inferred from the field measurements [Çemen et al., 2000], although we observe a much smaller slip variation. These junctions are associated with small changes in the fault strike $\left(3^{\circ}-4^{\circ}\right)$ and small extensional jogs. These minor geometric complexities may have influenced the dynamic rupture, possibly through some control on the preearthquake shear stress distribution or shear strength. The very linear geometry of the Izmit-Sapanca and Sapanca-Akyazi segments may have favored supershear rupture velocity [Bouchon et al., 2000]. This technique should not be seen as a substitute to field investigations since it cannot provide information about the complexities of the fault geometry and the slip distribution at a scale smaller than a few tens of pixels.

[11] At the moment, the SPOT technique only provides information about the location of surface ruptures and slip across the fault trace because the offset field is biased by the satellite motion which is not known with enough accuracy. It does complement but not substitute field measurements. A finer description of the satellite attitude than that provided for SPOT images might allow us to overcome this limitation. The technique might then become even more powerful and could reveal the fault's geometry at depth which remains very poorly constrained from available techniques (GPS and SAR in particular). The technique may also gain further interest with the advent of high-resolution satellite images and might also be applied to archived airborne photography.

\section{References}

Aochi, H., E. Fukuyama, and M. Matsu'ura, Spontaneous rupture propagation on a non-planar fault in 3-D elastic medium, Pure Appl. Geophys., 157, 2003-2027, 2000.

Armijo, R., B. Meyer, A. Hubert, and A. Barka, Westward propagation of the North Anatolian fault into the northern Aegean: Timing and kinematics, Geology, 27, 267-270, 1999.

Barka, A., The 17 August 1999 Izmit earthquake, Science, 285, $1858-$ 1859, 1999.

Barka, A., and K. Kadinsky-Cade, Strike-slip fault geometry in Turkey and its influence on earthquake activity, Tectonics, 7, 663-684, 1988.

Barka, A., O. Kozaci, S. Akyuz, and E. Altunel (Eds.), The 1999 Izmit and Duzce Earthquakes: Preliminary Results, Istanbul Tech. Univ., Istanbul, Turkey, 2000.

Bouchon, M., and D. Streiff, Propagation of a shear crack on a nonplanar fault: A method of calculation, Bull. Seismol. Soc. Am., 87, 61-66, 1997.

Bouchon, M., N. Toksöz, H. Karabulut, M. P. Bouin, M. Dietrich, M. Aktar, and M. Edie, Seismic imaging of the 1999 Izmit (Turkey) rupture inferred from the near-fault recordings, Geophys. Res. Lett., 27, 3013-3016, 2000.

Çemen, I., E. Gökten, B. Varol, R. Kiliç, V. Özaksoy, C. Erkmen, and A. Pinar, Turkish earthquakes reveal dynamics of fracturing along a major strike-slip fault zone, Eos Trans. $A G U, 81,309-313,2000$.

Crippen, R. E., Measuring of subresolution terrain displacements using SPOT panchromatic imagery, Episodes, 15, 56-61, 1992.

Ellsworth, W. L., and M. Celebi, Near field displacement time histories of the M 7.4 Kocaeli (Izmit), Turkey, earthquake of August 17, Eos Trans. $A G U, 80(46)$, Fall Meet. Suppl., F648, 1999.

Harris, R. A., and S. M. Day, Dynamic 3D simulations of earthquakes on en echelon faults, Geophys. Res. Lett., 26, 2089-2092, 1999.

Harris, R. A., R. J. Archuleta, and S. M. Day, Fault steps and the dynamic rupture process: 2-d numerical simulations of a spontaneously propagating shear fracture, Geophys. Res. Lett., 18, 893-896, 1991.

Harris, R. A., J. F. Dolan, R. Hartleb, and S. M. Day, The 1999 Izmit, Turkey earthquake-A test of the dynamic stress transfer model for intraearthquake triggering, Seismol. Res. Lett., 71, 223, 2000.

Hernandez, B., F. Cotton, and M. Campillo, Contribution of radar interferometry to a two-step inversion of the kinematics process of the 1992 Landers earthquake, J. Geophys. Res., 104, 13,083-13,099, 1999.

Hubert-Ferrari, A., A. Barka, E. Jacques, S. S. Nalbant, B. Meyer, R. Armijo, P. Taponnier, and G. C. P. King, Seismic hazard in the Marmara sea region following the 17 August 1999 Izmit earthquake, Nature, 404, 269-273, 2000.

Kase, Y., and K. Kuge, Numerical simulation of spontaneous rupture processes on two non-coplanar faults: The effect of geometry on fault interaction, Geophys. J. Int., 135, 911-922, 1998.

Massonnet, D., M. Rossi, C. Carmona, F. Adragna, G. Peltzer, K. Feigl, and T. Rabaute, The displacement field of the Landers earthquake mapped by radar interferometry, Nature, 364, 138-142, 1993.

McClusky, S., et al., Global Positioning System constraints on plate kinematics and dynamics in the eastern Mediterranean and Caucasus, J. Geophys. Res., 105, 5695-5719, 2000.

McGill, S. F., and C. M. Rubin, Superficial slip distribution on the central Emerson fault during the June 28, 1992, Landers earthquake, California, J. Geophys. Res., 104, 4811-4833, 1999.

Michel, R., J. P. Avouac, and J. Taboury, Measuring near field coseismic displacements from SAR images: Application to the Landers earthquake, Geophys. Res. Lett., 26, 3017-3020, 1999.

Okada, Y., Surface deformation due to shear and tensile faults in elastic half-space, Bull. Seismol. Soc. Am., 75, 1135-1154, 1985.

Parsons, T., S. Toda, R. S. Stein, A. Barka, and J. H. Dieterich, Heightened odds of large earthquakes near Istanbul: An interaction-based probability calculation, Science, 288, 661-665, 2000.

Peltzer, G., F. Crampé, and G. King, Evidence of nonlinear elasticity of the crust from the $M_{w}$ 7.6 Manyi (Tibet) earthquake, Science, 286, 272-276, 1999.

Reilinger, R. E., et al., Coseismic and postseismic fault slip for the 17 August 1999, $M=7.5$, Izmit, Turkey earthquake, Science, 289, 1519$1524,2000$.

Sibson, R. H., Rupture interaction with fault jogs, in Earthquake Source Mechanics, Geophys. Monogr. Ser., vol. 37, edited by S. Das, J. Boatwright, and C. Scholz, pp. 157-168, AGU, Washington, D. C., 1986.

Stein, R. S., The role of stress transfer in earthquake occurrence, Nature, 402, 605-609, 1999

Straub, C., and H. Kahle, GPS and geologic estimates of the tectonic activity in the Marmara Sea region, NW Anatolia, J. Geophys. Res., 102, 27,587-27,601, 1997.

Toksök, M. N., R. E. Reilinger, C. G. Doll, A. A. Barka, and N. Yalcin, Izmit (Turkey) earthquake of 17 August 1999: First report, Seismol. Res. Lett., 70, 669-679, 1999.

Tüysüz, O., and S. C. Genc, Geological factors controlling the distribution of damage during the 17th August and 12th November 1999 earthquakes, paper presented at the ITU-IAHS Conference on the Kocaeli Earthquake 17 August 1999, Istanbul Tech. Univ., Istanbul, 1999.

Van Puymbroeck, N., R. Michel, R. Binet, J. P. Avouac, and J. Taboury, Measuring earthquakes from optical satellite images, Appl. Opt., 39, 3486-3494, 2000.

Weldon, R., J. P. McCalpin, and T. Rockwell, Paleoseismology in strike-slip environments, in Paleoseismology, edited by J. P. McCalpin, pp. $271-$ 329, Academic, San Diego, Calif., 1996.

Wright, T., E. Fielding, and B. Parsons, Triggered slip: Observation of the 17 August 1999 Izmit (Turkey) earthquake using radar interferometry, Geophys. Res. Lett., 28, 1079-1082, 2001.

Yeats, R. S., K. Sieh, and C. Allen, The Geology of Earthquakes, Oxford Univ. Press, New York, 1997.

Zebker, H. A., P. Rosen, R. M. Goldstein, A. Gabriel, and C. L. Werner, On the derivation of coseismic displacement fields using differential radar interferometry: The Landers earthquake, J. Geophys. Res., 99, 19,61719,634, 1994 .

J.-P. Avouac and R. Michel, Laboratoire de Détection et de Géophysique, CEA, BP 12, F-91680 Bruyères-le-Châtel Cedex, France. (michel@dase. bruyeres.cea.fr) 

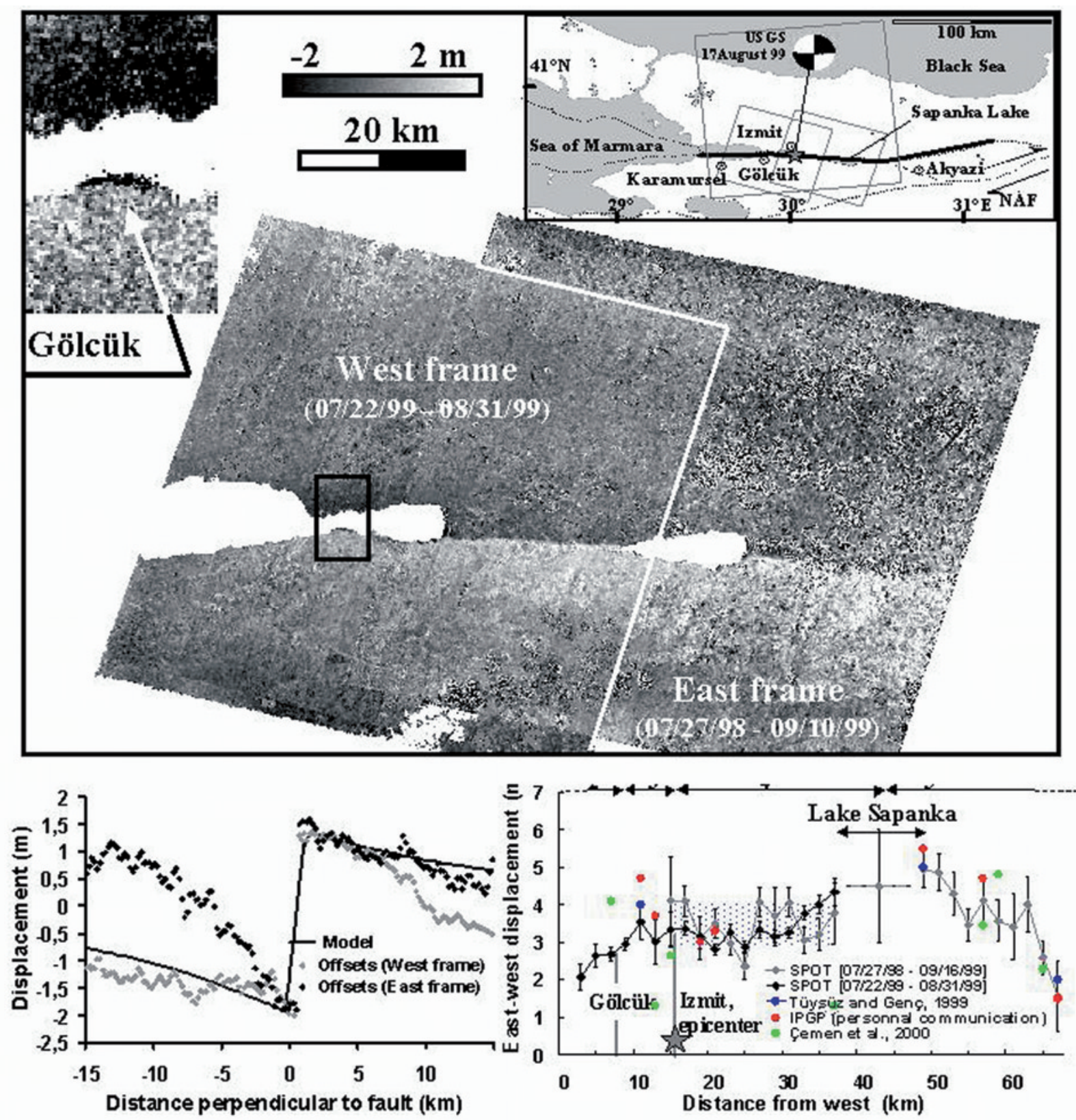

Figure 1. Ground displacement mapped from SPOT images. (a) E-W component of the displacement field computed from image pairs (KJ 102/268, SPOT-1 of 22 July 1999 and SPOT-2 of 31 August 1999) and (KJ 103/268, SPOT-2 of 27 July 1998 and SPOT-2 of 16 September 1999). The very linear discontinuity between Golcük and Akyazi coincides with the ruptures described from field survey. No deformation is visible out of this main fault zone. $\mathrm{N}-\mathrm{S}$ offsets are below the noise level. Tectonic setting, with main active faults, of the $M_{s}=7.4,17$ August 1999 Izmit earthquake is given in inset. Focal mechanism is from USGS catalog, and epicenter (star) is from Kandilli Observatory. Shaded boxes denote location of SPOT and ERS images. Black lines show approximate location of ruptures described from field investigations. (b) Stack of all profiles across fault zone from Izmit to Sapanca lake. Offsets show a clear jump at the fault trace, indicating a fault zone $<200 \mathrm{~m}$ wide. Mean slip is $3.5 \pm 0.2 \mathrm{~m}$. The two profiles differ due to uncertainty on SPOT changing attitude. Shaded line shows theoretical displacements derived from elastic modeling (Table 1). (c) Slip distribution between Gölcük and Akyazi measured from 1-km-wide swaths across the fault. Uncertainties are estimated from the variability of offsets on each side of the fault. The estimated slip at Sapanca lake is ascribed a large uncertainty because it is based on linear extrapolation of offsets across the lake. Field measurements are shown for comparison. 

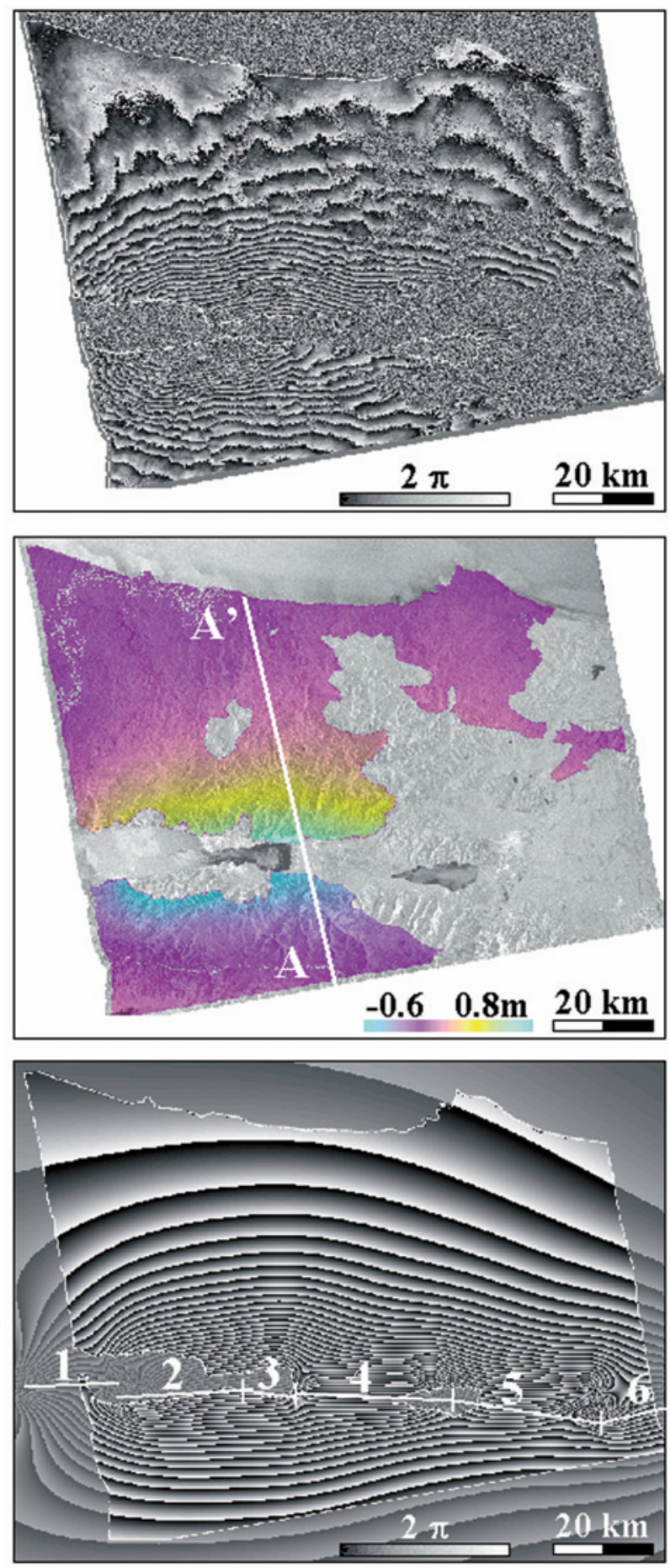

Figure 2. (opposite) Measured and modeled interferograms. (a) Differential SAR interferogram computed from ERS-2 SAR images (orbit frames 22556/815 and 23057/815) acquired on 13 August 1999 and 17 September 1999, respectively. A fringe represents $2.8 \mathrm{~cm}$ of ground shift away from satellite along the radar line of sight. Areas with a high level of noise result from temporal decorrelation. Near-fault areas are also poorly coherent due to either ground shaking or signal saturation. Interferogram is also affected by low-frequency noise (for wavelength larger than $\sim 10 \mathrm{~km}$ ) with an amplitude of a few fringes induced by atmospheric artifacts and residual errors in determination of orbits [e.g., Reilinger et al., 2000]. Orbital parameters tuned to remove a residual plane that cannot be explained by coseismic ground deformation. This linear correction amounts to three fringes in azimuth and four fringes in range. (b) Unwrapped interferogram. Phase unwrapping removes the $2 \pi$ ambiguity on measurements and yields relative displacements. Because the fault zone cuts across the interferogram, areas north and south of the fault zone are not related to the same reference frame, they were adjusted in order to fit elastic modeling. (c) Synthetic interferogram computed from the segmented fault model given in Table 1. We use an elastic halfspace dislocation model and consider vertical faults that reach the surface. Geometry and mean slip along the Karamürsel-Gölcük, Gölcük-Izmit, Izmit-Sapanca, and Sapanca-Akyazi segments were constrained from the offsets. The fault extents at depth and dip angle were adjusted for each segment. 